\title{
Respiratory Pattern Changes in Sleep in Children on Vagal Nerve Stimulation for Refractory Epilepsy
}

\author{
Lakshmi Nagarajan, Peter Walsh, Pauline Gregory, Stephen Stick, Jennifer Maul, \\ Soumya Ghosh
}

\begin{abstract}
Background: An altered breathing pattern in sleep, over two to three weeks, reported by the parents of a child on Vagal Nerve Stimulation (VNS) therapy for refractory epilepsy, prompted a sleep study in him. His polysomnography (PSG) revealed respiratory irregularity concordant with VNS activation. Dyspnoea is a well recognised and reported side effect of the VNS. However there are only a few studies looking at respiration in sleep with VNS. We therefore undertook PSGs in seven other children on VNS. Methods: Sleep studies were undertaken, in accordance with standard clinical practice. Sleep and apnoeas and hypopneas were scored in accordance with conventional criteria. Respiratory pattern changes in sleep (RPCS) with VNS were looked for. Results: Respiratory pattern changes in sleep were seen during PSG in seven of eight children on VNS for refractory epilepsy. Decreased effort and tidal volume occurred in seven children, concordant with VNS activation. In one child, this was associated with a fall in respiratory rate, in the other six children with an increase. No study showed an apnoea/hypopnoea index in the abnormal range. The RPCS were not associated with significant hypoxia or hypercapnoea. Conclusion: Our results suggest that RPCS occur in most children with VNS. This is not surprising in view of the significant influence vagal afferents have on respiratory control centres. The RPCS did not appear to have a clinical impact in our group. However further investigations are suggested to explore this phenomenon, especially in patients with sleep apnoea syndromes or compromised respiratory function.
\end{abstract}

RÉSUMÉ: Le pattern respiratoire change pendant le sommeil chez les enfants sous stimulation du nerf vague pour traiter une épilepsie réfractaire. Introduction: Une altération du pattern respiratoire pendant le sommeil sur une période de deux à trois semaines, notée par les parents d'un enfant sous stimulation du nerf vague (SNV) pour une épilepsie réfractaire, a motivé une étude du sommeil chez l'enfant. Son enregistrement polysomnographique (PSG) a montré des irrégularités respiratoires concordant avec la SNV. La dyspnée est un effet secondaire bien connu de la SNV. Cependant, il existe peu d'études sur la respiration pendant le sommeil sous SNV. Nous avons donc procédé à un enregistrement PSG chez sept autres enfants sous SNV. Méthodes: Les études du sommeil ont été réalisées selon les normes en pratique clinique. Le sommeil, les apnées et les hypopnées ont été évalués selon les critères conventionnels. Les changements du pattern respiratoire pendant le sommeil (CPRS) sous SNV ont été recherchés. Résultats: Des CPRS ont été observés pendant la PSG chez sept des huit enfants sous SNV pour épilepsie réfractaire. Une diminution de l'effort et du volume courant concordant avec la SNV a été observée chez sept enfants. Chez un enfant ceci était associé à une baisse de la fréquence respiratoire et chez les six autres à une augmentation. Aucune étude n'a montré un index apnée/hypopnée anormal. Les CPRS n'étaient pas associés à une hypoxie ou à une hypercapnie significative. Conclusions: Nos résultats suggèrent que des CPRS surviennent chez la plupart des enfants sous SNV, ce qui n'est pas étonnant considérant l'influence significative des afférents du nerf vague sur le contrôle des centres respiratoires. Les CPRS ne semblaient pas avoir un impact clinique chez nos patients. Il est indiqué d'explorer ce phénomène, surtout chez les patients qui présentent des syndromes d'apnée du sommeil ou une fonction respiratoire compromise.

Can. J. Neurol. Sci. 2003; 30: 224-227

Vagal nerve stimulation (VNS) is increasingly accepted world wide, as an adjunctive treatment option, with a favourable efficacy, safety and tolerability profile, for children and adults with intractable epilepsy. ${ }^{1-5}$ Respiratory pattern changes in sleep (RPCS) over two to three weeks, reported by the parents of a child on VNS therapy prompted a sleep study in this child. His polysomnography (PSG) revealed respiratory irregularity, concordant with VNS activation. Subsequently we specifically questioned all parents of children on VNS at our Centre ${ }^{6}$ regarding respiratory changes noted especially during sleep and undertook PSGs in seven of the children: two with reported
RPCS and five others who took up the offer to do a PSG. We present the results of the PSGs. None reported RPCS prior to VNS.

From the Princess Margaret Hospital for Children (LN, PW, PG, SS, JM) and the Centre for Neuromuscular and Neurological Disorders, UWA and Curtin University, Perth, Australia (SG).

Received July 11, 2002. AcCePted in finAl fORm February 24, 2003. Reprint requests to: L. Nagarajan, Department of Neurology, Princess Margaret Hospital for Children, PO Box D184, Perth WA 6840 Australia. 


\section{MethodS}

Sleep studies conformed to standard clinical practice and were acquired using an integrated PSG data acquisition and analysis package (Compumedics, Melbourne, Australia) and included EEG, EMG, EOG, respiratory movements (measured using qualitatively calibrated inductance plethysmography SensorMedics, Yorba Linda, Ca) and oronasal flow (detected using a thermistor - Edentec, Eden Prairie, MN), oximetry and transcutaneous carbon dioxide $\left(\mathrm{CO}_{2}\right)$ monitoring. Continuous transuctaneous $\mathrm{CO}_{2}$ measurements were intermittently corroborated with end tidal $\mathrm{CO}_{2}$. Central apnea was defined as absence of oronasal flow without respiratory effort lasting for three consecutive respiratory cycles. Obstructive apnea was defined as absence of flow despite respiratory effort for three consecutive respiratory cycles. Mixed apnea was defined as absent flow for three consecutive respiratory cycles with central and obstructive components. Hypopnea was defined as a $50 \%$ reduction in flow determined from the preceding 30 seconds of regular breathing and associated with a fall in oxygen saturation $\left(\mathrm{O}_{2} \mathrm{SAT}\right)$ of $4 \%$ or greater or an arousal. Sleep was scored in accordance with conventional criteria. ${ }^{7-8}$

\section{ReSUlts}

Case Reports (CR): Details of the eight children studied by PSG are shown in the Table.
CR1 (JT): has Lennox-Gastaut syndrome (LGS) of undetermined aetiology. Vagal nerve stimulation was implanted at age nine with a 75-90\% reduction in seizure frequency. He had been on the VNS for a year when his parents reported an alteration of his breathing pattern during sleep over two to three weeks - they stayed awake at night to monitor him. At that time his stimulus parameters were: stimulus intensity (SI) of $2 \mathrm{~mA}$ (milliamperes), pulse width (PW) of 500 microseconds $(\mu s)$, stimulus frequency (SF) of $30 \mathrm{~Hz}$, signal on time (ONT) of $30 \mathrm{~s}$ and stimulus off time (OFFT) of five minutes. He was investigated with a sleep PSG. This revealed relative hypopnoeas concordant with VNS activation. The relative hypopnoeas consisted of (qualitative) reduction in tidal volume (TV), reduction in respiratory rate $(\mathrm{RR})$ and reduction in minute ventilation (MV) (Figure 1). As illustrated in the Figure 1, the RPCS occurred only at the time of VNS stimulus delivery and were not present during OFFT. There often was a drop in $\mathrm{O}_{2} \mathrm{SAT}$ of $1-3 \%$, but no increase in $\mathrm{CO}_{2}$ levels. Interestingly, no clinical awakenings or EEG arousals were seen in association with these relative hypopnoeas. At different times over the next few months we reduced the SI (to $1.5 \mathrm{~mA}$ ), PW, SF, ONT and OFFT. Apart from a reduction in SI which appeared to transiently improve RPCS, there was no significant effect on PSG or RPCS, but his seizures did increase. Over the last year his VNS has been programmed at SI-2.25mA/SF-20Hz/PW-500 $\mu$ s/ONT-21s/OFFT 5 mins. Eighteen months since the onset of RPCS, he continues to benefit from VNS. His RPCS persists, but parents are less

Table: Details of eight children with VNS studies by PSG

\begin{tabular}{|c|c|c|c|c|c|c|c|c|}
\hline & CR1 & CR2 & CR3 & CR4 & CR5 & CR6 & CR7 & CR8 \\
\hline Name/Sex & $\mathrm{JT} / \mathrm{M}$ & $\mathrm{RW} / \mathrm{M}$ & $\mathrm{RB} / \mathrm{F}$ & $\mathrm{JH} / \mathrm{M}$ & $\mathrm{MB} / \mathrm{M}$ & $\mathrm{AC} / \mathrm{M}$ & $\mathrm{KM} / \mathrm{F}$ & $\mathrm{CG} / \mathrm{F}$ \\
\hline Age at VNS implant in years & 9 & 16 & 11 & 4 & 14 & 13 & 16 & 8 \\
\hline Age at onset of seizures & $3 \mathrm{yrs}$ & $4 \mathrm{yrs}$ & 19 days & $5 \mathrm{mths}$ & $5 \mathrm{mths}$ & 13 mths & $12 \mathrm{mths}$ & 4 yrs \\
\hline Seizure types & Multiple & Multiple & AA, GTC & Multiple & GTC, AA, NCS & CPS, GTC & CPS & CPS \\
\hline Seizure frequency prior to VNS & Innum. & Innum. & Innum. & Innum. & Innum. & $1 /$ day clusters + & $14 / \mathrm{mths}$ & Occas. \\
\hline No. of AEDs & 12 & 9 & 9 & 10 & 10 & 12 & 11 & 6 \\
\hline No of AEDs At VNS implant & 3 & 3 & 3 & 3 & 4 & 3 & 1 & 2 \\
\hline On VNS & 3 & 3 & 3 & 2 & 3 & 2 & 2 & 2 \\
\hline Intellectual Disability & Severe & Severe & Severe & Mild & Moderate & Mild & Severe & Moderate \\
\hline Duration of VNS at time of sleep study & 30 mths & $25 \mathrm{mths}$ & 22 mths & 48 mths & 15 mths & $28 \mathrm{mths}$ & 47 mths & 27 mths \\
\hline$\%$ reduced seizure frequency & $76-90$ & $>90$ & $50-75$ & $>90$ & 76-90 & $76-90$ & $76-90$ & $>90$ \\
\hline Tidal Volume & Decrease & Decrease & Decrease & Decrease & Decrease & Decrease & Decrease & No change \\
\hline Decrease in oxygen saturation & Yes & No & Yes & No & Yes & No & No & No change \\
\hline Parents report of RPCS & Yes & Yes & Yes & No & No & No & No & No \\
\hline
\end{tabular}

AA = atypical absence; $\mathrm{CPS}=$ complex partial seizure; GTC = generalised tonic clonic seizure; Multiple = > 3 seizure types; HIE = hypoxic ischaemic encephalopathy; NCS = nonconvulsive status; Innum. = innumerable; LKS = Landua-Kleffner Syndrome; LGS = Lennox Gastaut Syndrome; PE = partial epilepsy; AEDs = anti-epileptic drugs; $\mathrm{SI}=$ signal intensity in $\mathrm{Ma}, \mathrm{SF}=$ signal frequency in $\mathrm{Hz}, \mathrm{PW}=$ pulse width in microseconds, ONT = signal on time in seconds, OFFT = signal off time in minutes unless otherwise specified 


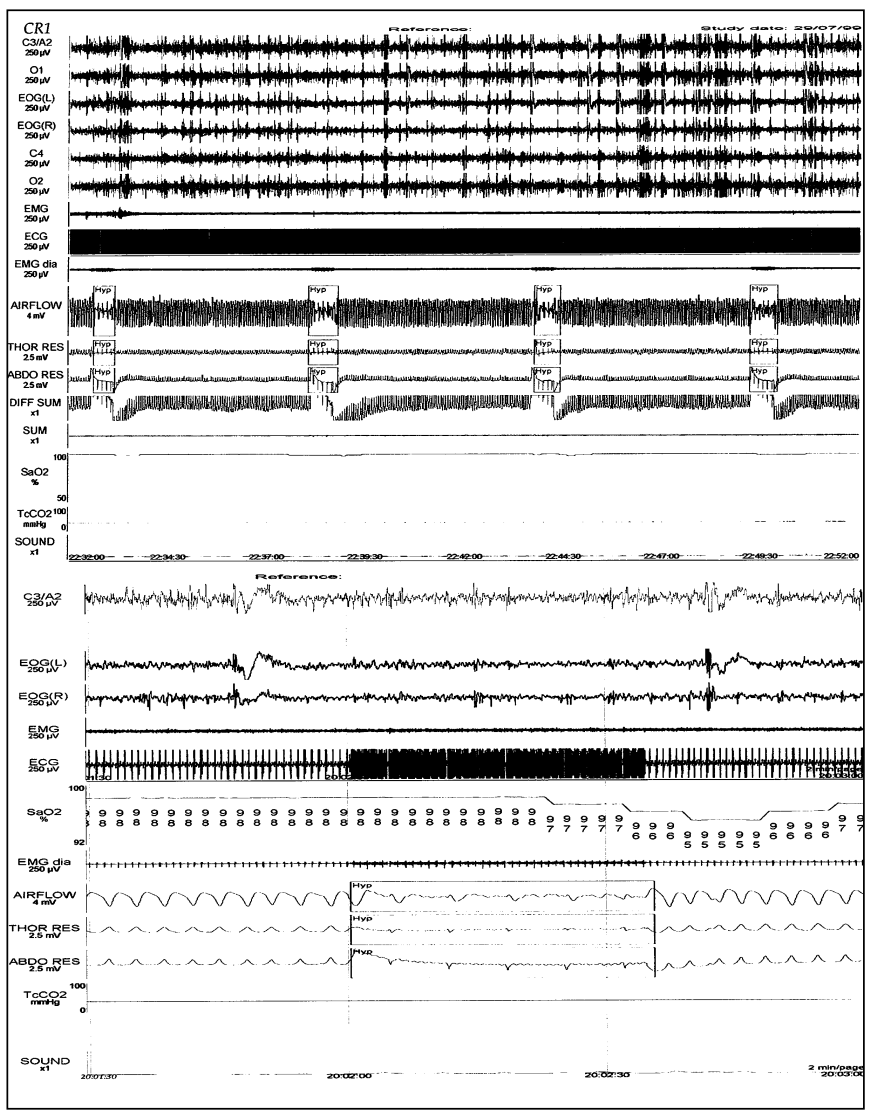

Figure 1: Respiratory pattern changes in sleep during VNS seen in CRI. Hyp indicates the RPCS seen when the VNS stimulus comes on. The top panel is at 20mins/page, the bottom at 2mins/page.

anxious and in repeated PSGs there has been no significant hypercapnoea or hypoxia. Parents did not at any time want the VNS to be turned off.

$\boldsymbol{C R} 2$ had the VNS implanted at 16 years for refractory seizures, with $>90 \%$ reduction in seizure frequency. On specific questioning, his parents reported mild RPCS. Polysomnography confirmed the RPCS. We saw increased RR and reduced TV (not $<50 \%$ ) (Figure 2). Minute ventilation was probably unchanged and there was no consistent change in the $\mathrm{O}_{2} \mathrm{SAT}$.

CR3 - CR7: In all five the RR was increased with VNS (only when the stimulus was on), along with a decrease in TV; in two (CR3\&CR5) the $\mathrm{O}_{2}$ SAT fell by less than $4 \%$, and was unchanged in three.

CR8: This child has Landau-Kleffner syndrome and started VNS at the age of eight. At the time of the PSG her stimulus parameters were in the fast cycling mode with SI-2.5mA, SF: 30Hz, PW:500us, ONT:7s and OFFT: 20s. No RPCS was seen and no respiratory irregularities were reported by her parents.

Sleep was difficult to score in CR1-5,7\&8. The changes with VNS activation were seen in REM and non-REM sleep. None of the studies showed an apnoea/ hypopnoea index in the abnormal range. None of the RPCS seen during the PSGs fulfilled criteria for apnoea/hypopnoea.

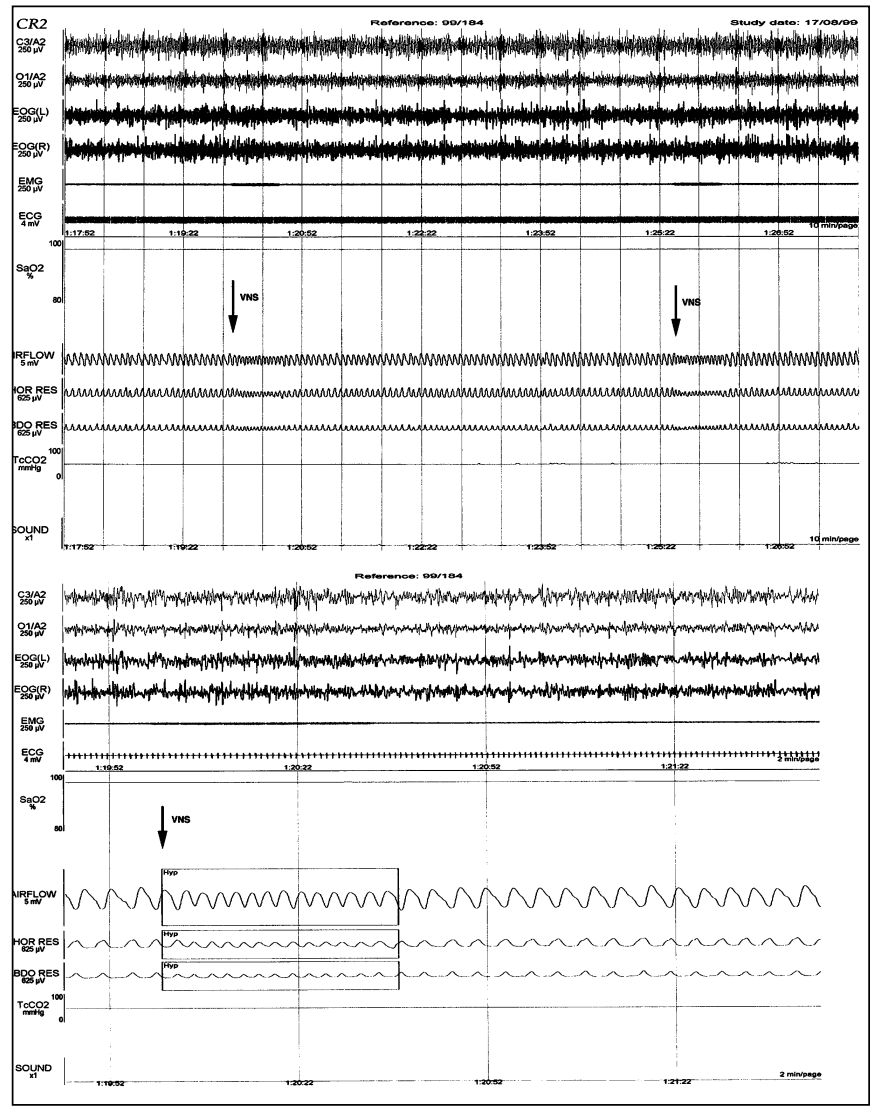

Figure 2: Respiratory pattern changes in sleep seen in CR2. The arrows indicate the VNS stimulus onset.

The top panel shows a sweep of 10mins/page and the bottom 2mins/page.

Stimulus parameters were not modified in CR2-8, since they appeared to be stable.

\section{Discussion}

Respiratory changes during sleep with VNS activation were seen in seven of eight children studied. In the eighth child changes may not have been evident to visual analysis as the VNS was in the rapid cycling mode. Our results suggest that RPCS (concordant with stimulus on time) occur in most children with VNS. The RPCS seen in six were very similar - an increase in $\mathrm{RR}$, decrease in TV and effort of breathing, and no significant change in MV. This would explain the absence of any significant changes in $\mathrm{O}_{2} \mathrm{SAT}$ or $\mathrm{CO}_{2}$ levels. In one child (CR1), however, $\mathrm{RR}$ decreased with VNS activation and there appeared to be central and obstructive elements to the RPCS seen. In three other children with refractory epilepsy, in whom VNS was planned to be implanted, no similar periodic RPCS was seen on pre-VNS PSG.

Dyspnoea has been reported as a side effect in several studies with VNS. ${ }^{1,3,4}$ Pulmonary function tests have shown remarkably little effect of VNS in humans ${ }^{3,4,9}$ though in animal studies respiratory abnormalities, including arrest have been reported. ${ }^{3}$ There is a paucity of studies looking at respiratory changes during sleep with the VNS. Malow et $\mathrm{al}^{10}$ have described similar 
changes in all four patients that they studied, with decreases in airflow and effort coinciding with VNS activation, that often did not meet criteria for apnoeas and hypopnoeas. Tachypnea associated with VNS activation has been shown by Malow et al ${ }^{10}$ and Murray et al. ${ }^{11}$ Amelioration of apnoeas and hypopnoeas with decrease in SF has been reported. ${ }^{10}$ We did not see this in the only patient (CR1) that we modified stimulus parameters. We have nevertheless left his SF at $20 \mathrm{~Hz}$.

Normal breathing is thought to be generated by "respiratory centres" in the medulla and pons. Several complex processes, voluntary and involuntary, are involved in generating the respiratory pattern. These respiratory controllers or pattern generators are postulated not only to have a pacemaker role, but also are dependant on and influenced by input from chemoreceptors and mechanoreceptors from the anatomical structures involved in the act of breathing, rostral pontine areas and higher cortical centres. ${ }^{12-13}$ Most sensory afferents that influence respiratory centres enter the brainstem through the vagus nerve and act through a variety of neurotransmitters and neuromodulators. ${ }^{14-15}$ The vagus nerve has widespread anatomical connections with brainstem nuclei, its afferent input reaching the nucleus of the tractus solitarius, nucleus ambiguus, area postrema, dorsal motor nucleus of the vagus, nucleus of the spinal tract of the trigeminal nerve and medial medullary reticular formation. The nucleus of the tractus solitarius has a large projection to the parabrachial nucleus, the reticular formation, and to many other nuclei in the brainstem, thalamus and higher cerebral centres. The antiepileptic effect of VNS is thought to be mediated through its effects on thalamocortical and brainstem networks and neuromodulators. ${ }^{16}$

Since vagal afferents have a significant influence on respiratory control centres, it is not surprising that we saw RPCS with VNS. What is intriguing is why RPCS is not more severe and does not occur in the wake state. The variability of effectiveness of different chemoreceptors in the wake vs sleep states, ${ }^{17}$ loss of wakefulness dependant descending influences on the brainstem respiratory controller, ${ }^{18}$ intrinsically unstable breathing patterns in sleep, ${ }^{19}$ changes in breathing pattern and upper airway dimensions seen in normal children during sleep, and the increased incidence of sleep apnoeas in patients with refractory epilepsy ${ }^{20}$ are probably all contributory factors to the RPCS with VNS. Vagal nerve stimulation-induced airway narrowing, altered sleep architecture, C fibre stimulation are some of the explanations offered for the changes seen in respiration during sleep on patients with VNS. ${ }^{10-11}$ Further studies are required to understand why RPCS occur with VNS and to explain the decrease in RR in CR1 as opposed to the increase in RR seen in the other children and in the previous reports.

Vagal nerve stimulation is a useful and safe therapeutic option in children with refractory epilepsy. ${ }^{1}$ Respiratory pattern changes in sleep with VNS were seen in seven of eight children reported here. Respiratory pattern changes in sleep with VNS did not meet our criteria for apnoea/hypopnoea in any child and there was no significant hypoxia or hypercapnia. Further investigations are suggested to explore RPCS with VNS, especially in those with sleep apnoeas or compromised respiratory function. The occurrence of RPCS with VNS has to be factored into the decision making process with regard to implantation of VNS for epilepsy.

\section{ACKNOWLEDGEMENTS}

We thank Ms Suzanne Muscat for her skilled secretarial service and the Medical Illustrations Department at PMH for their help.

\section{REFERENCES}

1. McLachlan RS. Vagus nerve stimulation for intractable epilepsy: a review. J Clin Neurophysiol 1997;14(5):358-368.

2. Schachter SC, Saper CB. Progress in epilepsy research, vagus Nerve stimulation. Epilepsia 1998;39(7):677-686.

3. Binnie CD. Vagus nerve stimulation for epilepsy: a review. Seizure 2000;9:161-169.

4. Labar D. Vagus nerve stimulation for intractable epilepsy in children. Dev Med Child Neurol 2000;42:496-499.

5. Valencia I, Holder D, Helmers S, et al. Vagus nerve stimulation in pediatric epilepsy: a review. Pediatr Neurol 2001:25:5;368-376.

6. Nagarajan L, Walsh P, Gregory P, et al. VNS therapy in clinical practice in children with refractory epilepsy. Acta Neurol Scand 2002;105:13-17.

7. Marcus CL, et al. Normal polysomnographic values for children and adolescents. Am Rev Respir Dis 1992;146(5 Pt 1):1235-1239.

8. The Atlas Task Force, EEG arousals: scoring rules and examples. Sleep 1992;15(2):173-183.

9. Banzett RB, Guz A, Padarafar D, et al. Cardiorespiratory variables and sensation during stimulation of the left vagus in patients with epilepsy. Epilepsy Res 1999;35:1-11.

10. Malow BA, Edwards J, Marzed M et al. Effects of vagus nerve stimulation on respiration during sleep. Neurology 2000;55: 1451-1454.

11. Murray JM, Matheson JK, Scammell TE. Effects of vagus nerve stimulation on respiration during sleep. Neurology 2001;57:1523.

12. Remmers JE. Central Neural Control of Breathing. In: Atose M, Kawakami Y (Eds). Control of Breathing in Health and Disease Vol. 135. New York: Marcel Dekker, Inc. 1999:1-35.

13. Khoo MC. Determinants of ventilatory instability and variability. Respir Physiol 2000;122 (2-3):167-182.

14. Burton MD, Kazemi H. Neurotransmitters in central respiratory control. Respir Physiol 2000;122(2-3):111-121.

15. Lagercrantz H. Classical and "new" neurotransmitters during development - some examples from control of respiration. J Dev Physiol 1984:6(3);195-205.

16. Henry TR. Anatomical, experimental, and mechanistic investigations. In: Schachter SC, Schmidt D (Eds). Vagus Nerve Stimulation, London: Martin Dunitz Limited, 2001;1-30.

17. Nattie E. Multiple sites for central chemoreception: their roles in response sensitivity and in sleep and wakefulness. Respir Physiol 2000;122(2-3):223-235.

18. Remmers JE. Sleeping and breathing. Chest Mar 1990;97(3):77S$80 \mathrm{~S}$.

19. Hamans E, Boudewyns A, De Backer W, et al. Sleep related breathing disorders: the respiratory control system and its instability during sleep. Acta Otorhinolaryngol Belg 1995;49(1):45-51.

20. Malow BA, Levy K, Maturen K, et al. Obstructive apnoeas is common in medically refractory epilepsy. Neurology 2000;55:1002-1007. 